\title{
Nutritional Status Among Orphans and Vulnerable Children Aged 6 to 59 Months in Addis Ababa, Ethiopia: A Community-Based Cross-Sectional Study
}

Nina Berr

Myungsung Medical College

Yemisrach Nigatu

Myungsung Medical College

Nebiyu Dereje ( $\square$ neba.jahovy@gmail.com )

Myungsung Medical College

\section{Research Article}

Keywords: HIV/AIDS, stunting, wasting, underweight, orphans, vulnerable children

Posted Date: January 28th, 2021

DOl: https://doi.org/10.21203/rs.3.rs-151460/v1

License: (c) (i) This work is licensed under a Creative Commons Attribution 4.0 International License.

Read Full License

Version of Record: A version of this preprint was published at BMC Nutrition on April 26th, 2021. See the published version at https://doi.org/10.1186/s40795-021-00431-5. 


\section{Nutritional status among orphans and vulnerable children aged 6 to 59}

2 months in Addis Ababa, Ethiopia: A community-based cross-sectional study

3 Nina Berr ${ }^{1}$, Yemisrach Nigatu ${ }^{2}$, Nebiyu Dereje ${ }^{3 *}$

41 Department of Medicine, Myungsung Medical College/Myungsung Christian Medical

5 Center, Addis Ababa, Ethiopia

$6 \quad$ Email nina.berr@yahoo.de

72 Department of Public Health, Myungsung Medical College/Myungsung Christian

$8 \quad$ Medical Center, Addis Ababa, Ethiopia

$9 \quad$ Email yemisrachmmc@gmail.com

103 Department of Public Health, Myungsung Medical College/Myungsung Christian

11 Medical Center, Addis Ababa, Ethiopia

12 Email neba.jahovy@gmail.com

$14 *$ Corresponding author:

15 Nebiyu Dereje

16 Addis Ababa, P.O.Box 14972, Ethiopia

17 Phone Number: +251978788638

18 Email: neba.jahovy@gmail.com 


\section{Abstract}

Background: Childhood malnutrition is a global problem contributing to more than a third of under-five mortality. Orphans and vulnerable children (OVC) fare worse than children living with their parents. However, the nutritional and healthcare needs of OVC are underrecognized in Ethiopia.

Methods: A community-based cross sectional study was conducted among OVC aged 6 to 59 months. Multi-stage sampling technique was applied to select the households and eligible children included in the study $(\mathrm{n}=584)$. An interviewer-administered questionnaire and anthropometric measurements were carried out. The proportions of stunting, wasting and underweight were determined based on the WHO Z-score cut-off. Multivariable binary logistic regression analysis was performed to identify factors associated with stunting.

Results: The prevalence of stunting, wasting and underweight were $35.1 \%$ (95\% CI; $31.3 \%$ $39.1 \%), 4.7 \%(95 \% \mathrm{CI} ; 3.2 \%-6.7 \%)$ and $12.0 \%$ (95\% CI; $9.6 \%-14.9 \%$ ), respectively. Stunting was significantly associated with initiation of complementary feeding after 12 months of age $(\mathrm{AOR}=3.61 ; 95 \%$ CI $1.16-14.11)$, household food insecurity $(\mathrm{AOR}=1.90$; 95\% CI 1.10 - 3.17), unplanned pregnancy (AOR $=1.90 ; 95 \%$ CI $1.03-3.42)$, age $\geq 2$ years $(\mathrm{AOR}=1.80 ; 95 \% \mathrm{CI} 1.25-2.67)$, caretaker's age $\leq 25$ years $(\mathrm{AOR}=1.50 ; 95 \% \mathrm{CI} 1.03-$ 2.16) and employment of the caretaker ( $\mathrm{AOR}=1.50 ; 95 \% \mathrm{CI} 1.03-2.26)$.

Conclusion: The prevalence of all forms of malnutrition among OVC was significantly higher than the national estimate. Most importantly, this study uncovers that the positive health statistics which point towards decreases in under nutrition as evidenced by consecutive Ethiopian Demographic and Health Surveys (EDHS) data do not accurately reflect the condition of the many underprivileged children living in the society. These findings of the 
42 study underscore the need for interventions to enhance household food security and

43 caretaker's awareness on child feeding particularly addressing the OVC.

44 Key words: HIV/AIDS, stunting, wasting, underweight, orphans, vulnerable children 


\section{Introduction}

Malnutrition among children is a global problem hindering individuals and entire nations from achieving their full potential [1-3]. Globally more than a third of under-five deaths are linked to under nutrition [4]. The attribution of HIV/AIDS for the child mal-nutrition is enormous [1-3].

Ethiopia has managed to achieve the targets set by Millennium Development Goals (MDG 4), namely reducing by two thirds the under-five mortality rate between 1990 and 2015 three years prior to the deadline [5, 6]. Moreover, Ethiopia has reduced the prevalence of malnutrition under five markedly over the years and is committed to reducing malnutrition further through the National Nutrition Strategy Programmes [7]. Nutrition is also firmly embedded as a priority in the country's Health Sector Transformation Plan [8]. For instance, the prevalence of stunting, the predominant form of under nutrition, has been reduced to 25.4\% in urban areas and only $14.6 \%$ in the capital Addis Ababa according to EDHS 2016 [7]. However, these figures are likely to rest on statistics which obscure the poverties endured by poorer urban children and the OVC, as Ethiopia is located in Sub-Saharan Africa, where the prevalence of HIV/AIDS and OVC are substantial $[3,4,9]$. Studies have shown that when child health statistics are unravelled, it is evident that even where services are nearby, children growing up in poor urban settings fare as badly as or worse than children living in rural poverty in terms of under nutrition and under-five mortality $[4,10]$.

An orphan or vulnerable child is a child who is at high risk of lacking adequate care and protection due to parental death, disease, disaster or acute poverty. The term orphan can be further defined as a child whose mother (maternal orphan), father (paternal orphan) or both (double orphan) have died [3, 11]. Researchers have long been intrigued by the question whether orphans and vulnerable children (OVC) living in the community suffer more malnutrition than non-orphans. The current literature on this matter shows conflicting results. 
Studies in various countries across the African continent including Kenya, the United Republic of Tanzania and Zimbabwe have shown that OVC are more malnourished than their counterparts. Particularly the proportion of stunting and underweight was markedly higher and OVC had overall poorer health outcomes $[10,12,13]$. On the other hand, many studies suggest otherwise including an analysis of national survey data in Sub-Saharan Africa on under-five children in 40 countries, which found no differences in the nutritional status of orphans and non-orphans [14]. Therefore, the question of whether orphans are more malnourished than non-orphans remains unclear and seems to differ from one society to the other. Up to this day, there are only few studies in Ethiopia that look at the nutritional status of less fortunate children such as OVC and no such studies have been conducted in the capital city of Addis Ababa where the prevalence of HIV/AIDS and OVC is substantial. Hence, it is the aim of this study to bridge the gap by assessing the nutritional status and associated factors of OVC living in Addis Ababa city, Ethiopia.

\section{Methods}

\section{Study setting, Design and Population}

A community-based cross sectional study was conducted from May 01 - 31, 2019 in Addis Ketema Sub-city, one of the ten sub-cities of Addis Ababa. It is a densely populated sub-city consisting of ten districts covering an area of only $8.64 \mathrm{~km}^{2}$ with a total population estimated at 320,000 as of 2017 . The total number of orphaned children due to HIV and other causes was 20,655 in 2017 in the sub-city. All OVC aged 6 to 59 months who had been living in the study area for a period of at least 6 months were eligible for inclusion and only the youngest child was selected per household. OVC who were severely ill or disabled were excluded due to the difficulty of obtaining accurate measurements. Also, OVC who were not found in three appointed interviews were excluded from the study and replaced by the next eligible OVC. 
Furthermore, children whose caretakers have a hearing difficulty preventing them from being interviewed were excluded.

\section{Sampling Procedures}

Sample size for the prevalence of stunting, wasting and under nutrition was determined by a single population proportion formula by taking prevalence of stunting (35.1\%), the most common form of malnutrition which was taken from a study done among OVC in Hawassa town in 2016 [15], $\mathrm{Z} \alpha / 2=1.96,5 \%$ margin of error, $10 \%$ non-response rate and 1.5 design effect. The calculated sample size was 584. The sample size for the analytical component (factors associated with stunting) was determined by a two population proportion formula by taking $80 \%$ power, $95 \%$ confidence interval $(\mathrm{CI}), 5 \%$ margin of error, proportion of stunting among literate care givers and proportion of stunting among illiterate care givers from the study conducted in Gondar [16]. The sample size calculated from this formula was 190. Thus, we took the largest possible sample size $(n=584)$ in our study.

A multi-stage sampling technique was employed to recruit study participants. In the first stage, out of the ten districts, three of them were selected randomly. Then, the total sample size was distributed to each district proportionally to the total households of the district. Social workers living in the community who are collaborating closely with the sub-city identified the households at risk wherein OVC reside in their respective villages of the selected districts. In order to facilitate the data collection, one social worker accompanied each data collector to the OVC households until the sample size was completed. In households with more than one child aged 6 to 59 months, only the youngest OVC was selected. Many of the households received financial support as part of the safety net program. However, none of the children received any form of nutritional support. 
Data were collected by using structured questionnaire (supplementary material attached) and anthropometric measurements performed by the data collecting team with identical scales, measuring boards and MUAC tapes. The questionnaire was adapted from various sources including UNICEF [15, 17]. It has several contents including socio-demographic characteristics, housing and sanitation, feeding practices and dietary diversity, morbidity variables and household food insecurity. It was initially prepared in English and translated into Amharic language for data collection.

Data collection was facilitated by nurses and facilitators who were social workers familiar with the OVC in selected households. Fieldworkers were given training by the principal investigator on the objectives and methodology of the study, the contents of the questionnaire, the confidentiality of responses, the use of instruments and standard procedure of anthropometric measurement.

Height was measured in standing position for children $\geq 2$ years and length was measured in recumbent position in children $<2$ years. The child was barefooted and free of head wear. For measuring height the child was helped onto the baseboard with feet slightly apart. The back of the head, shoulder blades, buttocks, calves and heels were touching the vertical board. The assistant held the child's knees and ankles. With the child's chin held between thumb and forefinger and eyes facing directly forward, the interviewer pulled the headboard down to rest firmly on top of the child's and read to the nearest completed $0.1 \mathrm{~cm}[18,19]$. For measuring length the child was placed on its back. The assistant standing opposite the tape held the child's head against the headboard. The child's eyes were looking straight up. The interviewer standing on the side of the measuring tape held down the child's knees with the left hand and moved the footboard with the right hand flat against the soles. The measurement was read and recorded to the nearest completed $0.1 \mathrm{~cm}[19]$. 
Weight was measured with the child lightly dressed on a standard scale and recorded to the nearest $0.1 \mathrm{~kg}$. For children $<2$ years of age, the caretaker was first weighed alone and again holding the undressed child. The difference between the two readings equalled the weight of the child. The scale was calibrated immediately before each session [19].

MUAC is the circumference of the undressed left upper-arm measured at the mid-point between the shoulder tip and elbow in children with a height $>65 \mathrm{~cm}$. The interviewers bent the arm of the child at the elbow and identified and marked the olecranon and acromion processes as well as the midpoint between the two landmarks with a pen. Then, the arm was straightened and hung down the side of the body. The tape was placed around the arm at the marked mid-point at correct tape tension and the circumference was read to the nearest $0.1 \mathrm{~cm}$ and repeated twice to ensure accuracy. Colour coding indicates nutritional status [19].

\section{Ethical Considerations}

Ethical clearance was obtained from the Institutional Review Board (IRB) of Myungsung Medical College. The participants were informed about the objective of the study and written informed consent was gained from the caretakers. Illiterate caretakers were asked to sign the consent form after it was read to them by the interviewer. Moreover, the participants were at no risk of serious harm and had the right to decline participation or withdraw at any time and anonymity guaranteed by the principal investigator.

\section{Data Management and Analysis}

Age was documented in completed months. If the caretaker was unsure of the child's day of birth, the $15^{\text {th }}$ day of the month was used and if the month of birth was unknown the midpoint of the year was used [15]. Food security was assessed using the Household Food Insecurity 
Access Scale (HFIAS) specifically adapted by the USAID Food and Nutrition Technical Assistance (FANTA) project for use in developing countries as a measure of the degree of food insecurity in the household in the past four weeks. Households were considered foodsecure if they scored less than 17 and food-insecure if they scored $\geq 17$ points [17]. Dietary Diversity Scores were calculated by adding the number of food groups consumed in the household over the 24-hour recall period and graded as low $(\leq 3)$ and high $(\geq 4)$ based on the WHO designation of minimum dietary diversity if four or more food groups consumed in the last 24 hours [15]. The prevalence of malnutrition was assessed by calculating the percentages of children who are stunted, wasted or underweight using ENA SMART based on the WHO 2 Z-score cut-off and summarized by percentage and the respective $95 \%$ confidence interval. Bivariate and multi-variable binary logistic regression analyses were carried out to identify factors associated with stunting. Those variables with $\rho$-value $<0.25$ in the bivariate analysis were considered for further multi-variable analysis and $\rho$-values of less than 0.05 were taken as a cut-off point for determining the significant association of independent variables with stunting. Odds ratio (OR) with $95 \%$ confidence interval was calculated to determine the strength of associations. All methods were carried out in accordance with relevant guidelines and regulations.

\section{Results}

\section{Socio-demographic Characteristics}

The response rate of the study was $98.6 \%$. Majority of the participants $(52.9 \%)$ were female and ranged from 12 - 23 months in age (27.0\%). On average, each household had 4.4 members and 1.25 children under the age of five. Among the participants, $13.4 \%$ were orphans. Most caretakers were married (69.2\%) and close to one third (30.5\%) were illiterate (unable to read and write). Over half of the households had a monthly income less than or equalling 1,000 Ethiopian Birr (ETB), below the international poverty line of $\$ 1.90$ per day 
193 [20]. The majority (87.3\%) of households consisted of only a single room as living space 194 (Table 1).

195 Table 1. Socio-demographic characteristics of the study participants in Addis Ketema sub196 city, Addis Ababa, Ethiopia

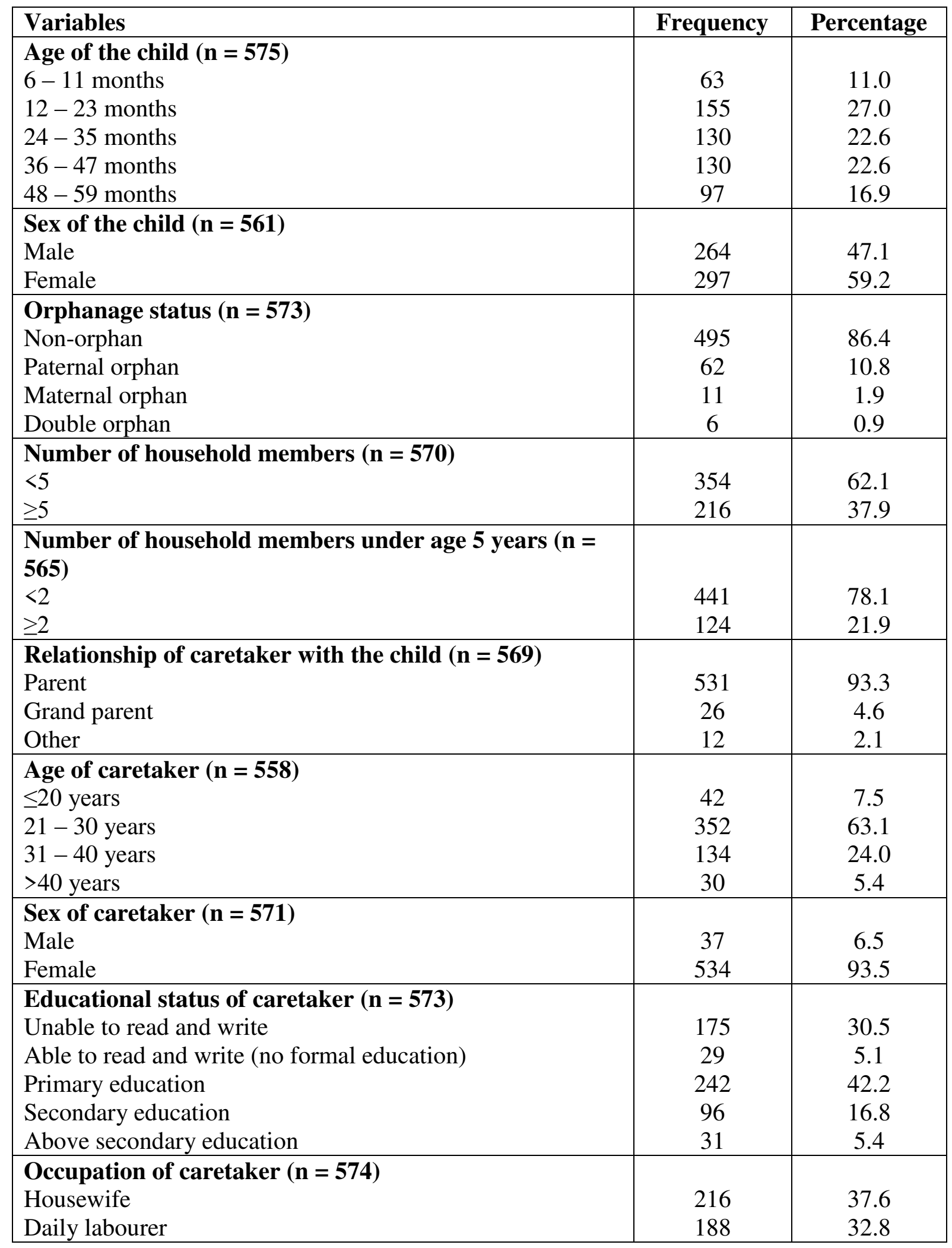




\begin{tabular}{|l|c|c|}
\hline Unemployed & 74 & 12.9 \\
Other & 95 & 15.8 \\
\hline Marital status of caretaker $(\mathbf{n}=\mathbf{5 7 1})$ & 47 & \\
Single & 395 & 6.2 \\
Married & 85 & 14.9 \\
Divorced & 44 & 7.7 \\
Widowed & & \\
\hline Family monthly income (ETB) $(\mathbf{n}=\mathbf{4 9 3})$ & 121 & 24.5 \\
$\leq 600$ & 275 & 55.8 \\
$601-1650$ & 77 & 15.6 \\
$1651-3200$ & 20 & 4.0 \\
\hline 3200 & & \\
\hline
\end{tabular}

197

Feeding practices and dietary diversity

Nearly all $(92.8 \%)$ children were exclusively breastfed during the first six months but only a

third $(31.0 \%)$ were breastfed for the recommended 24 months. Vaccination coverage was

practically universal at $98.1 \%$ but only around three quarters $(73.4 \%)$ were said to have received complete vaccination for age or had taken Vitamin A in the last six months $(70.9 \%)$.

Four-fifths (79.2\%) of household were considered food secure and 57.2\% of children had a minimum dietary diversity while almost half $(43.8 \%)$ had consumed less than four food groups in the last 24 hours prior to the survey (Table 2).

Table 2. Feeding practices and dietary diversity among OVC, Addis Ketema Sub-city, Addis Ababa, Ethiopia

\begin{tabular}{|l|c|c|}
\hline Variables & Frequency & Percentage(\%) \\
\hline Was the child breastfed? $(\mathbf{n = 5 7 3 )}$ & 559 & 97.6 \\
Yes & 14 & 2.4 \\
\hline No & & \\
\hline Initiation of breastfeeding $(\mathbf{n = 5 5 5 )}$ & 546 & 98.4 \\
\hline First hour & 9 & 1.6 \\
\hline After first hour & & \\
\hline Exclusive brestfeeding $(\mathbf{n = 5 5 3 )}$ & 513 & 92.8 \\
Yes & 40 & 7.2 \\
\hline No & & \\
\hline Total duration of breastfeeding in months $(\mathbf{n = 3 0 0 )}$ & 28 & 9.3 \\
\hline 6 & 34 & 11.3 \\
\hline 6 to 11 & 46 & 15.3 \\
\hline 12 to 17 & 25 & 8.3 \\
\hline 18 to 23 & \\
\hline
\end{tabular}




\begin{tabular}{|l|c|c|}
\hline$\geq 24$ & 167 & 55.7 \\
\hline Initiation of complementary feeding (n=557) & 21 & 3.8 \\
At birth & 83 & 14.9 \\
Birth to 6 months & 438 & 78.6 \\
6 months to 12 months & 15 & 2.8 \\
after 12 months & & \\
\hline Type of first complementary food $(\mathbf{n = 5 5 6})$ & 156 & 28.0 \\
Formula milk & 106 & 19.1 \\
Cow milk & 180 & 32.4 \\
Porridge & 114 & 20.5 \\
Adult food & & \\
\hline Method of complementary feeding $(\mathbf{n = 5 5 6})$ & 144 & 25.9 \\
Hand & 284 & 51.1 \\
Cup and spoon & 128 & 23.0 \\
Bottle & & \\
\hline Dietary Diversity Score $(\mathbf{n}=\mathbf{5 5 9})$ & 239 & 42.8 \\
\hline Low $(<4)$ & 320 & 57.2 \\
\hline High $(\geq 4)$ & & \\
\hline
\end{tabular}

209 Prevalence of stunting, wasting and underweight

210 The prevalence of stunting, wasting and underweight were $35.1 \%$ (95\% CI; 31.3\% - 39.1\%),

$2114.7 \%(95 \% \mathrm{CI} ; 3.2 \%-6.7 \%)$ and $12.0 \%(95 \% \mathrm{CI} ; 9.6 \%-14.9 \%)$ respectively in OVC living

212 in Addis Ketema Sub-city, Addis Ababa. The distribution of the mal-nutrition by sex is given

213 in Figure 1. 


\section{Prevalence of malnutrition in OVC}

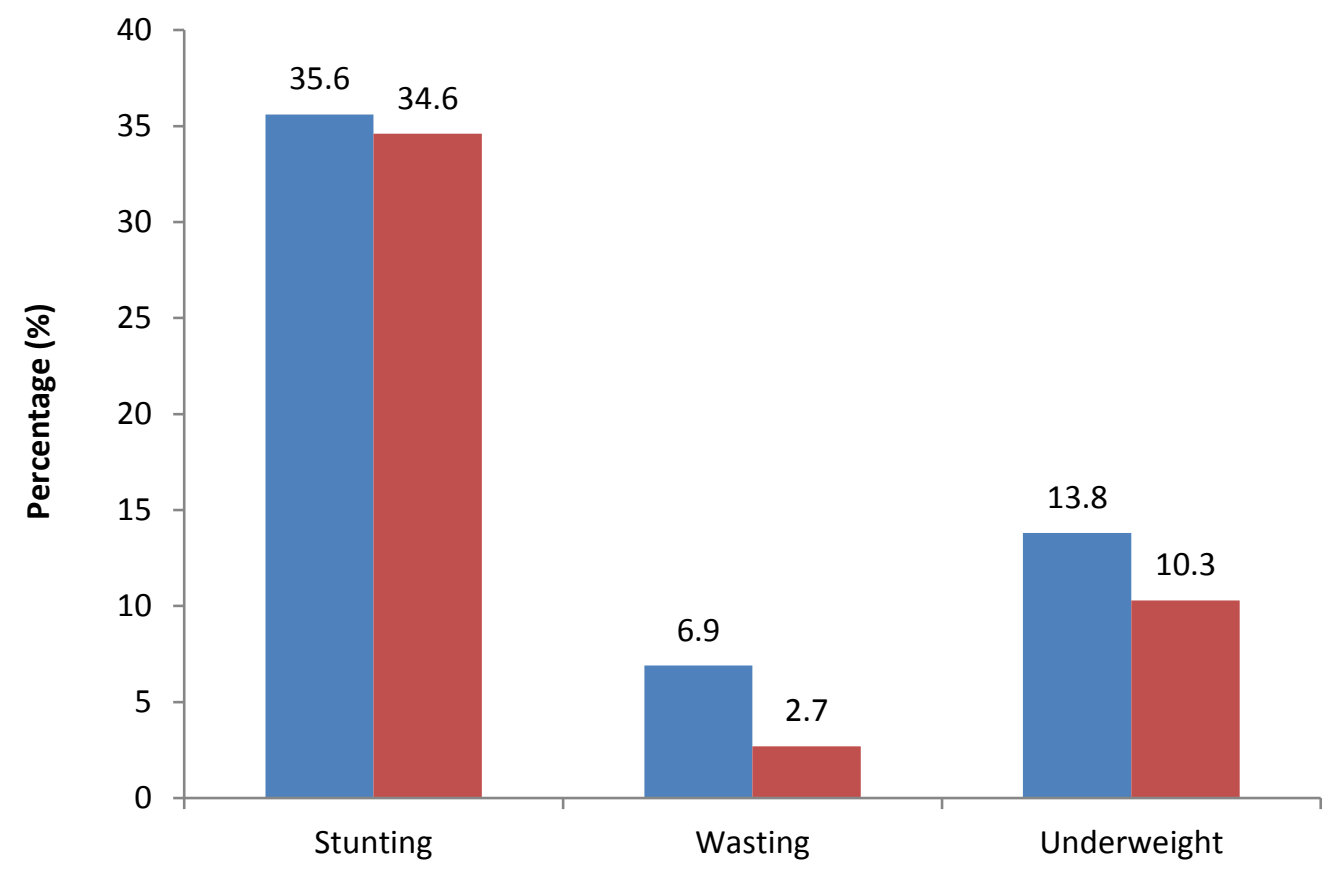

Figure 1: Prevalence of malnutrition among OVC in Addis Ketema Sub-city, Addis Ababa,

Ethiopia

\section{Factors associated with stunting}

In the bivariate analysis, age of the child, age of the care-taker, occupation of the care-taker, monthly income, planned pregnancy, maternal antenatal care follow up, breast feeding status, duration of breast feeding, place of birth, time of initiation of complementary feeding, household food insecurity were identified as candidate variables for further multi-variable analysis. However, in the further multi-variable analysis (Table 3), stunting was significantly associated with initiation of complementary feeding after 12 months of age, household food insecurity, unplanned pregnancy, age $\geq 2$ years, caretaker's age $\leq 25$ years and employment of the caretaker. The odds of stunting among those OVC who initiate complementary feeding after 12 months of age was four times higher (AOR $=3.57 ; 95 \%$ CI $1.32,7.62)$ as compared to those OVC who initiate complementary feeding within $6-12$ months of age. The odds of 
stunting among those OVC with household food insecurity were two times higher $(\mathrm{AOR}=$

1.86; $95 \%$ CI 1.10, 3.17) than those OVC with household food security. Similarly, the odds

230 of stuning was two times higher among OVC age $\leq 23$ months and care-taker's age $\leq 25$ years

231 as compared to their counterparts. The odds of stunting was 1.5 times higher $(\mathrm{AOR}=1.53$;

$23295 \%$ CI 1.03, 2.26) among those OVC whose care-taker was employed as compared to those

233 OVC whose care-taker was housewife.

234 Table 3. Factors associated with stunting among OVC in Addis Ketema sub-city, Addis 235 Ababa, Ethiopia

\begin{tabular}{|c|c|c|c|c|c|}
\hline \multirow[t]{2}{*}{ Variables } & \multicolumn{2}{|c|}{ Stunting } & \multirow[t]{2}{*}{ COR (95\% CI) } & \multirow[t]{2}{*}{ AOR $(95 \%$ CI $)$} & \multirow{2}{*}{$\begin{array}{c}P \\
\text { value }\end{array}$} \\
\hline & $\begin{array}{c}\text { Yes } \\
\mathrm{N}(\%)\end{array}$ & $\begin{array}{c}\mathrm{No} \\
\mathrm{N}(\%)\end{array}$ & & & \\
\hline $\begin{array}{l}\text { Age of the child } \\
\leq 23 \text { months } \\
24-59 \text { months }\end{array}$ & $\begin{array}{l}156(41.7) \\
218(58.3)\end{array}$ & $\begin{array}{c}62(31.0) \\
138(69.0)\end{array}$ & $\begin{array}{c}1.00 \\
1.60(1.12,2.40)\end{array}$ & $\begin{array}{c}1.00 \\
1.82(1.25,2.67)\end{array}$ & 0.004 \\
\hline $\begin{array}{l}\text { Age of the care-taker } \\
\leq 25 \text { years } \\
>25 \text { years }\end{array}$ & $\begin{array}{l}114(30.6) \\
259(69.4)\end{array}$ & $\begin{array}{l}79(39.3) \\
122(60.7)\end{array}$ & $\begin{array}{c}1.47(1.03,2.11) \\
1.00\end{array}$ & $\begin{array}{c}1.49(1.03,2.16) \\
1.00\end{array}$ & 0.026 \\
\hline $\begin{array}{l}\text { Occupation of the care- } \\
\text { taker } \\
\text { Housewife } \\
\text { Employed } \\
\text { Unemployed }\end{array}$ & $\begin{array}{l}154(42.2) \\
163(44.7) \\
48(13.2) \\
\end{array}$ & $\begin{array}{c}62(31.2) \\
111(55.8) \\
26(13.1) \\
\end{array}$ & $\begin{array}{c}1.00 \\
1.69(1.16,2.48) \\
1.35(0.77,2.36) \\
\end{array}$ & $\begin{array}{c}1.00 \\
1.53(1.03,2.26) \\
1.35(0.76,2.40) \\
\end{array}$ & $\begin{array}{l}0.031 \\
0.293\end{array}$ \\
\hline $\begin{array}{l}\text { Time of initiation of the } \\
\text { complementary feeding } \\
\text { Birth to } 6 \text { months } \\
6-12 \text { months } \\
>12 \text { months }\end{array}$ & $\begin{array}{c}74(20.5) \\
281(77.8) \\
6(1.7)\end{array}$ & $\begin{array}{c}29(14.9) \\
157(80.5) \\
9(4.6)\end{array}$ & $\begin{array}{c}0.70(0.44,1.12) \\
1.00 \\
3.69(1.36,7.68)\end{array}$ & $\begin{array}{c}0.68(0.31,1.49) \\
1.00 \\
3.57(1.32,7.62)\end{array}$ & $\begin{array}{l}0.353 \\
0.003\end{array}$ \\
\hline $\begin{array}{l}\text { Planned pregnancy } \\
\text { Yes } \\
\text { No }\end{array}$ & $\begin{array}{c}324(88.5) \\
42(11.5)\end{array}$ & $\begin{array}{c}165(82.5) \\
36(17.2)\end{array}$ & $\begin{array}{c}1.00 \\
1.68(1.12,2.86)\end{array}$ & $\begin{array}{c}1.00 \\
1.87(1.13,3.42)\end{array}$ & 0.032 \\
\hline $\begin{array}{l}\text { Household food } \\
\text { insecurity } \\
\text { Secure } \\
\text { Insecure }\end{array}$ & $\begin{array}{c}304(81.9) \\
67(18.1)\end{array}$ & $\begin{array}{l}149(74.1) \\
52925.9)\end{array}$ & $\begin{array}{c}1.00 \\
1.58(1.09,2.45)\end{array}$ & $\begin{array}{c}1.00 \\
1.86(1.10,3.17)\end{array}$ & 0.015 \\
\hline
\end{tabular}




\section{Discussion}

239 The present study revealed that under nutrition among OVC less than five years of age is much higher than that was reported by Mini- EDHS 2019 at which the prevalence of stunting, wasting and underweight in Addis Ababa was 13.9\%, 2.3\% and 4.7\%, respectively [21]. Although there is an overall decreasing trend of under nutrition among children less than five years of age, the findings of this study revealed that among underprivileged children, the prevalence is still high. At $35.1 \%$ and $12.0 \%$, the prevalence of stunting and underweight among OVC in Addis Ketema Sub-city is more than 2.5 times higher than their counterparts living in Addis Ababa. Similarly, the prevalence of wasting (4.7\%) is double that of their peers. This discrepancy could reflect that the EDHS might not represent the minority groups such as the OVC and may lead to underestimation of the prevalence of under nutrition in the children.

Although this study shows a high prevalence of stunting among OVC, it did not reveal that orphan-hood itself is significantly associated with stunting in the vulnerable children. Moreover, no significant association has been identified between the type of orphan (double, maternal, paternal) and chronic malnutrition. It should be noted however, that the proportion of orphans (13.4\%) was relatively low and a greater percentage of orphans may have produced more results. This is in contrast to a study done in Hawassa and Dilla, Ethiopia, where about a quarter of the participants were orphans. It showed that children whose parents were not alive were more likely to be stunted [15, 22]. Also, a study in Zimbabwe in 2007 revealed that maternal and paternal orphans had statistically significantly heightened risks of stunting [10]. On the other hand, the results of a study published in Uganda in 2013 showed that there was no statistical difference in the prevalence of chronic malnutrition between 
orphans $(17.0 \%)$ and non-orphans $(17.2 \%)$ and is thus more consistent with the results of this study [23]. Therefore, this study concludes that while vulnerable children suffer more malnutrition than their care-takers, the lack of a parent is not a contributing factor in the population studied.

Consistent with the study conducted in Gondar, Ethiopia, this study revealed that children older than two years had significantly higher odds of stunting [16]. This could be explained by the lower socio-economic status of the care-takers to serve optimal meals for the children once they initiate foods. In the earlier ages, children often get the recommended optimal nutrition from breast feeding [2].

The strongest association with stunting was found in children in whom complementary feeding was initiated after 12 months of age. This was not demonstrated by other studies. Rather a study done in Hawassa that examined the type of first complementary food, found that children whose first food was porridge were more likely to be stunted as compared to those with milk as their first diet [15].

Children from households which were classified as food insecure based on the Household Food Insecurity Access Scale (HFIAS) had nearly doubled odds of being stunted. While the study in Hawassa showed identical trends it was not proven to be statistically significant [15]. Another study that was conducted in Kenya in 2010 examined household food security among orphans in the capital Nairobi. While orphans were much more vulnerable to food insecurity than non-orphans, orphans did not display a higher proportion of stunting and thus household food insecurity was not a significant determinant of stunting unlike in this study [13]. This discrepancy might be attributed by the differences in the socio-demographic status between the study participants. 
Other interesting findings of this study include that children whose principal caretaker was employed as opposed to being a housewife had higher proportions of stunting, while other studies failed to identify such a relationship between caretaker employment and stunting. One likely explanation may be that children whose caretaker was housewife, had longer durations of breastfeeding. Other associated factors of stunting identified in this study include age of caretaker $\leq 25$ years and unplanned pregnancy. These findings can be explained by the fact that younger care takers might not be interested in child care or may not have adequate knowledge towards child care.

This study is the first study to determine the prevalence of malnutrition among the orphans and vulnerable children in Addis Ababa using a community based design. However, the findings of the study might be affected by the recall and social-desirability bias of the care takers.

\section{Conclusions}

The prevalence of stunting, wasting and underweight among the OVC was found to be significantly higher than their counterparts living in the capital city, Addis Ababa. Most importantly, this study uncovers that the positive health statistics which point towards decreases in under nutrition as evidenced by consecutive EDHS data do not accurately reflect the condition of the many underprivileged children living in the society. Therefore, these children and their caretakers will likely benefit from on-going efforts of screening, nutritional interventions and education on feeding practices.

\section{List of Abbreviations}
AIDS
Acquired Immunodeficiency Syndrome

AOR

Adjusted Odds Ratio 
309 CI

310 EDHS

311 ENA

312 ETB

313 FANTA

314 HFIAS

315 HIV

316 MUAC

317 OVC

318

319

320

WHO
Confidence Interval

Ethiopian Demographic Health Survey

Emergency Nutrition Assessment

Ethiopian Birr

Food and Nutrition Technical Assistance

Household Food Insecurity Access Scale

Human Immunodeficiency Virus

Mid-Upper Arm Circumference

Orphans and Vulnerable Child

United Nations Children's Fund

United States Agency for International Development

World Health Organization

\section{Declarations}

\section{Ethics approval and consent to participate}

323 Ethical clearance was obtained from the Institutional Review Board (IRB) of Myungsung

324 Medical College. The participants were informed about the objective of the study and written

325 informed consent was gained from the caretakers.

\section{Consent for publication}

327 Not applicable 


\section{Availability of data and material}

329 Data is available upon reasonable request from the corresponding author.

330

331

332

333

334

335

336

337

338

339

\section{0}

341

342

343

344

345

346

347

348

\section{Competing interests}

The authors declare that they have no competing interests.

\section{Funding}

Funding of this study was obtained from Myungsung Medical College. The funder had no role in the design, conduct, analysis and interpretation of this study.

\section{Authors Contributions}

NB, YN and ND made substantial contributions to conception and design, acquisition of data, analysis and interpretation of data; took part in drafting the article or revising it critically for important intellectual content; agreed to submit to the current journal; gave final approval of the version to be published; and agree to be accountable for all aspects of the work.

\section{Acknowledgements}

The study was supported by Myungsung Medical College, Myungsung Christian Medical Center, UNICEF and MSF-Spain. The assistance of the Women and Children's Affairs Office of Addis Ketema Subcity Administration was of utmost importance for the successful conduction of the data collection. Last but not least, gratitude goes out to all the families who participated in this study for their willingness and cooperation. 


\section{References}

350 1. Wakhweya A, Dirks R, Yeboah K. Children thrive in families: family centered models

351 of care and support for orphans and other vulnerable children affected by HIV and AIDS.

352 AIDS JLICA. 2008.

353 2. Rivers J, Silvestre E, Mason J. Nutritional and Food Security Status of Orphans and

354 Vulnerable Children: Report of a Research Project supported by UNICEF, IFPRI, and WFP.

355 International Food Policy Research Institute from http://www ifpri org/themes/HIV/hivpubs 356 asp. 2004.

357 3. Mishra VK, Bignami-Van Assche S. Orphans and Vulnerable Children in High HIV358 prevalence Countries in Sub-Sahara Africa: Marco International Incorporated; 2008.

359 4. Aslam A, Grojec A, Little C, Maloney T, Tamagni J. The State of the World's 360 Children 2014 in Numbers: Every Child Counts. Revealing Disparities, Advancing Children's 361 Rights: ERIC; 2014.

362 5. Ruducha J, Mann C, Singh NS, Gemebo TD, Tessema NS, Baschieri A, et al. How 363 Ethiopia achieved millennium development goal 4 through multisectoral interventions: a 364 countdown to 2015 case study. The Lancet Global Health. 2017;5(11):e1142-e51.

365 6. Ki-Moon B. The millennium development goals report 2013. United Nations Pubns. 3662013.

367 7. Agency CS. Ethiopian Demographic and Health Survey. Addis Ababa, Ethiopia: 2016.

368 8. FMoH E. Health Sector Transformation Plan. HSTP 2015/16-2019/20. August, 2015.

369 9. Andrews G, Skinner D, Zuma K. Epidemiology of health and vulnerability among 370 children orphaned and made vulnerable by HIV/AIDS in sub-Saharan Africa. AIDS care. $371 \quad 2006 ; 18(3): 269-76$.

372 10. Watts H, Gregson S, Saito S, Lopman B, Beasley M, Monasch R. Poorer health and 373 nutritional outcomes in orphans and vulnerable young children not explained by greater 
exposure to extreme poverty in Zimbabwe. Tropical medicine \& international health. 2007;12(5):584-93.

376 11. Skinner D. Defining orphaned and vulnerable children: HSRC Press; 2004.

377 12. Lindblade KA, Odhiambo F, Rosen DH, DeCock KM. Health and nutritional status of 378 orphans $<6$ years old cared for by relatives in western Kenya. Tropical Medicine \& 379 International Health. 2003;8(1):67-72.

380 13. Braitstein P, Ayaya S, Nyandiko WM, Kamanda A, Koech J, Gisore P, et al. 381 Nutritional status of orphaned and separated children and adolescents living in community 382 and institutional environments in Uasin Gishu County, Kenya. PLoS One. 2013;8(7):e70054.

383 14. Monasch R, Boerma JT. Orphanhood and childcare patterns in sub-Saharan Africa: an 384 analysis of national surveys from 40 countries. Aids. 2004;18:S55-S65.

385 15. Bisrat G, Kulkarni U. Assessment of the nutritional status and associated factors of 386 orphans and vulnerable preschool children on care and support from Nongovernmental Organizations in Hawassa Town, Southern Ethiopia. Global Journal of Medical Research. 2017;16(2):1-41.

16. Gultie T, Sisay E, Sebsibie G. Nutritional status and associated factors among orphan 390 children below the age of five years in Gondar City, Ethiopia. J Food Nutr Sci. 2014;2(4):179-84. for measurement of food access: indicator guide: version 3. 2007.

18. De Onis M, Onyango AW, Borghi E, Garza C, Yang H, Group WMGRS. Comparison of the World Health Organization (WHO) Child Growth Standards and the National Center for Health Statistics/WHO international growth reference: implications for child health programmes. Public health nutrition. 2006;9(7):942-7. 
400 20. Jolliffe D, Prydz EB. Estimating international poverty lines from comparable national 401 thresholds: The World Bank; 2016.

402 21. Agency CS. Mini demographic and health survey 2019; Key indicators. Addis Ababa, 403 Ethiopia: 2019.

404 22. Wete AT, Zerfu TA, Anbese AT. Magnitude and associated factors of wasting among 405 under five orphans in Dilla town, southern Ethiopia: 2018: a cross-sectional study. BMC 406 nutrition. 2019;5(1):33.

407 23. Moses L. Orphans and Vulnerable Children (OVC) in Uganda: Are orphans more 408 malnourished than non-orphans. Social Sciences. 2013;2(2):58-65. 
Figures

\section{Prevalence of malnutrition in OVC}

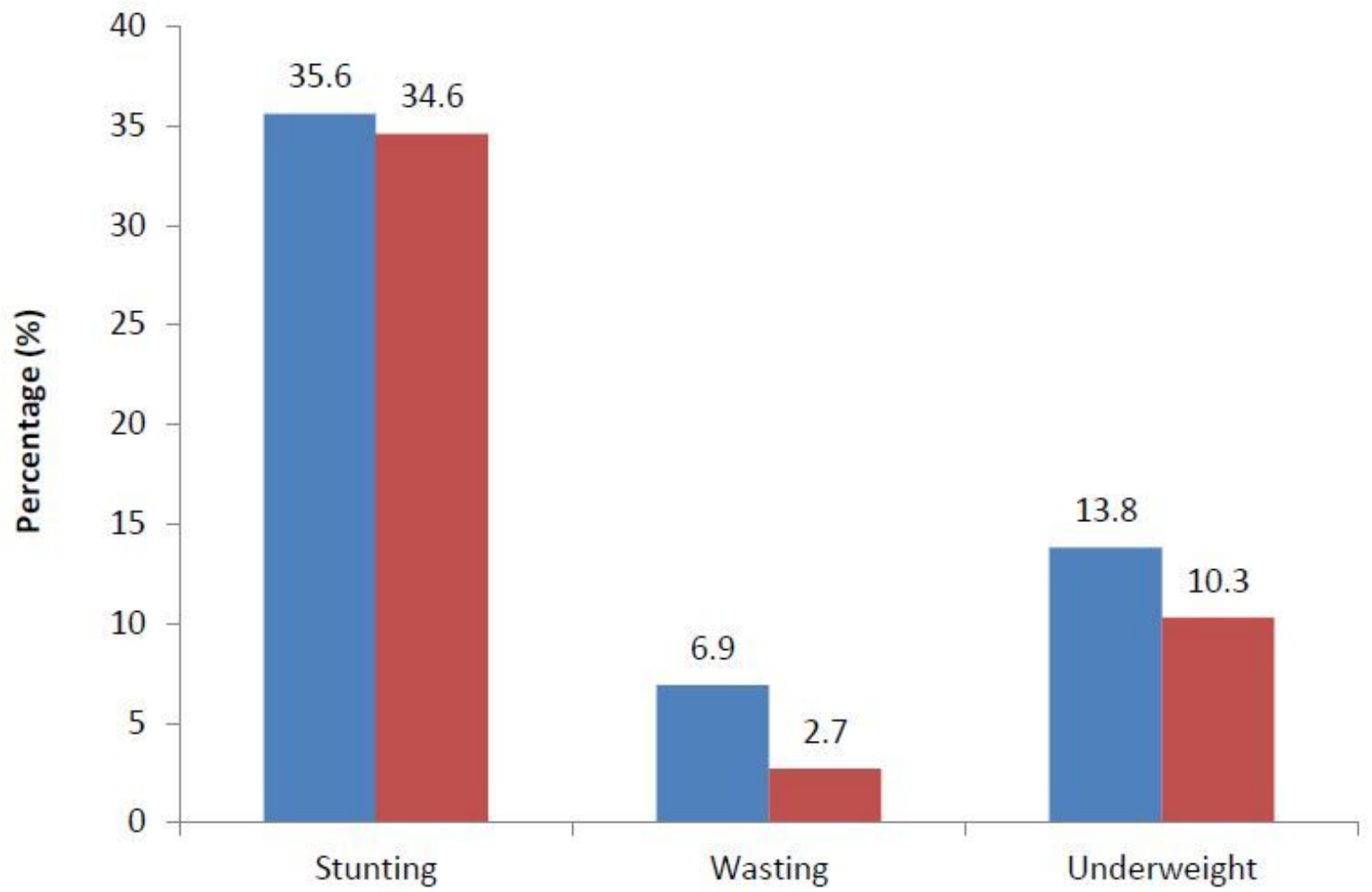

Figure 1

Prevalence of malnutrition among OVC in Addis Ketema Sub-city, Addis Ababa, Ethiopia

\section{Supplementary Files}

This is a list of supplementary files associated with this preprint. Click to download.

- Questionnaire.pdf 